\title{
SIMULATION AND MEASUREMENT OF WINDOWS WITH LOW EMISSIVITY COATINGS USED IN CONJUNCTION WITH TEFLON* INNER GLAZINGS
}

\author{
John L. Wright, Prof. H.F. Sullivan \\ Advanced Glazing System Laboratory \\ Department of Mechanical Engineering \\ University of Waterloo \\ Waterloo, Ontario, Canada
}

N2L 3G1

\begin{abstract}
Theoretical work has illustrated that highly infrared transparent plastic films are well suited for use as intermediate glazings when used in conjunction with a low emissivity coating. Prototype glazing systems that incorporate low emissivity coatings and Teflon films were constructed. The thermal resistance of each of these prototypes was measured using the University of Waterloo Natural Convection : Apparatus. Simulation of the glazing systems was carried out using a two-band glazing system thermal analysis program called VISION. Comparison between measurement and simulation showed good agreement. It can be concluded that highly infrared transparent intermediate glazings can be useful when high thermal resistance is desired and that the VISION glazing system analysis program

- is useful not only for parametric and sensitivity investigations but can also be used with confidence to estimate $\mathrm{U}$-values of specific glazing systems.
\end{abstract}

\section{KEYWORDS}

Glazing; Window; Low E; Teflon; U-value; Shading Coefficient

\section{INTRODUCTION}

Wright (1985) and Hollands and Wright (1983) have illustrated that highly infrared (IR) transparent plastic films are well suited for use as intermed-

iate glazings if used in conjunction with a low emissivity (low-E) coating. The availability of low-E coatings has provided the opportunity to successfully design glazing systems with plastic films (Since most plastics are significantly $\mathrm{IR}^{+}$transparent). Teflon (FEP) film was chosen for study because of its excellent chemical and UV stability, very high solar and visible transmittance, high IR transmittance and off-the-shelf availability.

* $\quad$ Registered trademark of I.E. duPont de Nemour and Co.

+ "infrared" (IR), "thermal" and "long wave" are used inchangeably to describe wavelengths greater than $3 \mu \mathrm{m}$. 
The current research extends this work. Prototype glazing systems that incorporate low-E coatings and Teflon films were constructed. The thermal resistance of each of these prototypes was measured using the University of Waterloo Natural Convection Apparatus. This apparatus is a guarded heater plate type device that can be used, in a modified form, for the accurate measurement of heat flux through glazing systems. Simulation of the same glazing systems was carried out using a glazing system thermal analysis program called VISION. VISION provides reliable estimates of glazing system $U$-value and shading coefficient. The algorithm used to quantify heat transfer is capable of modelling partially IR transparent glazings. This capability is of particular importance since thin Teflon films are significantly transparent in the thermal wavelength band.

\section{THE GLAZING SYSTEMS}

The four glazing systems simulated and tested consisted either of plain Teflon film or conventional window glass with or without a low-E coating. All of the glazing systems consisted of two panes of glass separated by either $0,1,2$ or 3 Teflon films used as intermediate glazings. In each case, the warm-side glass pane had a low-E coating on the surface facing the other glazing(s). = The fourth glazing system had a second low-E coating on the cold-side glass pane - again on the surface facing the other glazings.

The solar optical properties of the glass were characterized using the index of refraction, $\mathrm{n}=1.52$, and extinction coefficient, $\mathrm{K}=0.024 \mathrm{~mm}^{-1}$. The glass lites were $6 \mathrm{~mm}$ thick. Similar data used to describe Teflon were $\mathrm{n}=1.344$ and $\mathrm{K}=0.0 \mathrm{~mm}^{-1}$. All Teflon glazings were $0.0254 \mathrm{~mm}$ thick and uncoated.

Table 1 shows the solar and long wave optical properties that were used to - model the glazings that were studied. Visible transmittance is also listed in - Table 1. The visible transmittance values and solar transmittance and relectance values are for normal incidence. The long wave properties are

hemispheric/hemispheric values. The solar and visible property values for

both plain and coated glass were provided by the manufacturer.

\section{TABLE 1 Summary of Optical Properties}

\begin{tabular}{lllll} 
Optical & Low E on Glass & Teflon & Glass \\
Property & \#1 & $\# 2$ & -1 & - \\
\hline Solar Transmittance & 0.57 & 0.57 & 0.96 & 0.795 \\
Solar Reflectance (coated side) & 0.35 & 0.35 & 0.04 & 0.072 \\
Solar Reflectance (uncoated side) & 0.20 & 0.20 & & \\
Visible Transmittance & 0.83 & 0.83 & 0.96 & 0.875 \\
Long Wave Emissivity & 0.067 & 0.070 & 0.243 & 0.84 \\
Long Wave Transmittance & 0.0 & 0.0 & 0.634 & 0.0
\end{tabular}

The hemispheric/normal long wave reflectances of the low $E$ coatings on glass were measured using a Gier-Dunkel DB-100 Infrared Reflectometer and converted to the values shown in Table 1 using electromagnetic theory (Siegel and Howell, 1972). The solar optical properties of Teflon are based on the manufacturer's literature and on measurement (Sibbitt and Hollands, 1976). The long wave optical properties of Teflon are also based on measurement (Wilkinson, 1979).

! The long wave reflectivity data reported for Teflon by Wright (1980) were in error and were, in fact, absorptivity values. 


\section{MEASUREMENT AND SIMULATION RESULTS}

Heat transfer testing of four prototype glazing systems was carried out using the University of Waterloo Natural Convection Apparatus. This equipment is described fully by ElSherbiny, Raithby and Hollands (1982). Each glazing system tested was placed between two flat copper plates. The copper plates and the glazing systems were square and measured $635 \mathrm{~mm}$ by $635 \mathrm{~mm}$. To prevent direct contact between the copper and glass surfaces, and to promote good thermal contact, neoprene sheets of $3.18 \mathrm{~mm}$ ( $1 / 8$ inch) nominal thickness were placed between the glazing system and the copper plates. The panes of each glazing system were separated by edge spacers made of rigid insulating foam.

The copper plates were maintained at different but constant temperatures by fluid that was pumped from two constant temperature circulating baths to manifolds attached to the backs of the copper plates. The temperature difference between the copper plates, $\Delta \mathrm{T} p$, was measured using a copper/constantan thermopile - each plate containing six thermocouples.

The warmer of the two copper plates contains three guarded heater plates, each measuring $200 \mathrm{~mm}$ by $200 \mathrm{~mm}$. Thermal resistance values reported here resulted from measurements of heat flux at the heater plate located in the centre of the warm copper plate where the heat transfer through the glazing system is assumed to be one dimensional and free of edge effects.

Details of the experimental procedure used to balance the heater plates are provided by Wright and Sullivan (1987). The glass-to-glass thermal conductance of the glazing system, $\mathrm{C}_{\text {meas }}$, was calculated using equation $\cdot 1$.

$$
\begin{aligned}
& \mathrm{C}_{\text {meas }}= {\left[\left(\mathrm{A}_{\mathrm{hp}} \Delta \mathrm{T}_{\mathrm{p}} / \mathrm{Q}_{e}\right)-2 \mathrm{R}_{\mathrm{n}}\right]^{-1} \quad \mathrm{~W} / \mathrm{m}^{2} \mathrm{C} } \\
& \text { where, } \mathrm{A}_{\mathrm{hp}}=\text { heater plate area }=0.03919 \mathrm{~m}^{2} \\
& \mathrm{R}_{\mathrm{n}}=\text { thermal resistance of neoprene sheet }=0.017 \mathrm{~m}^{2} \mathrm{C} / \mathrm{W} \\
& \mathrm{Q}_{e}=\text { electrical power supplied to the heater plate, } \mathrm{W}
\end{aligned}
$$

Each prototype system was simulated using a modified version of the VISION program. The program modification involved substituting the thermal resistance of the neoprene sheet, $R_{n}$, for the thermal resistance that would normally be accounted for between the glazing system and its environment. The glass-to-glass conductance, $\mathrm{C}_{\text {VISION }}$, was then calculated using equation 2 .

$$
\begin{array}{ll}
\mathrm{C}_{\text {VISION }}=\mathrm{q}_{\text {tot }} /\left(\mathrm{T}_{2}-\mathrm{T}_{\mathrm{n}-1}\right) \quad \mathrm{W} / \mathrm{m}^{2} \mathrm{C} \\
\text { where, } & \mathrm{q}_{\text {tot }}=\text { total heat flux through the glazing system }\left(\mathrm{W} / \mathrm{m}^{2}\right) \\
& \mathrm{T}_{2}=\text { temperature of glass adjacent warm copper plate }(\mathrm{C}) \\
& \mathrm{T}_{\mathrm{n}-1}=\text { temperature of glass adjacent cold copper plate (C) }
\end{array}
$$

The measured and simulated C-value results for the prototype glazing systems are shown in Table 2. In addition, all of the glazing systems have been simulated using VISION (in its unmodified form) and the U-values for ASHRAE winter and summer design conditions, $U_{w}$ and $U_{s}$, respectively, as well as the shading coefficient (SC) are reported in Table 2. The measured and calculated C-value results shown in Table 2 agree well. The largest discrepancies noted were $10 \%$. The temperature levels, $\mathrm{T}_{\text {hot }}$ and $\mathrm{T}_{\text {cold }}$, shown in Table 2 are the constant temperature bath settings.

Fig. 1 shows a cross section of glazing system GS3 (See Table 2) and 
TABLE 2 Comparison of Simulated and Measured C-Values

\begin{tabular}{|c|c|c|c|c|c|c|c|c|}
\hline & $\begin{array}{l}\text { W E } \\
\text { tings }\end{array}$ & $\begin{array}{l}\mathrm{T}_{\text {cold }} \\
\text { (C) }\end{array}$ & $\begin{array}{l}\text { \# Teflon } \\
\text { Films }\end{array}$ & $\begin{array}{c}\mathrm{C}_{\text {meas }} \\
\left(\mathrm{W} / \mathrm{m}^{2} \mathrm{C}\right)\end{array}$ & $\begin{array}{l}\mathrm{C}_{\text {VISION }} \\
\left(\mathrm{W} / \mathrm{m}^{2} \mathrm{C}\right)\end{array}$ & $\begin{array}{c}\mathrm{U}_{\mathrm{W}} \\
\left(\mathrm{W} / \mathrm{m}^{2} \mathrm{C}\right)\end{array}$ & $\begin{array}{c}\mathrm{U}_{\mathrm{S}} \\
\left(\mathrm{W} / \mathrm{m}^{2} \mathrm{C}\right.\end{array}$ & SC \\
\hline GSI & 1 & $\begin{array}{r}0.0 \\
-10.0 \\
\end{array}$ & 0 & $\begin{array}{l}2.61 \\
2.46 \\
\end{array}$ & $\begin{array}{l}2.47 \\
2.62 \\
\end{array}$ & 1.83 & 1.87 & 0.61 \\
\hline GS2 & 1 & $\begin{array}{r}0.0 \\
-10.0 \\
\end{array}$ & 1 & $\begin{array}{l}1.69 \\
1.67 \\
\end{array}$ & $\begin{array}{l}1.64 \\
1.61 \\
\end{array}$ & 1.25 & 1.45 & 0.59 \\
\hline GS3 & 1 & $\begin{array}{r}0.0 \\
-10.0 \\
\end{array}$ & 2 & $\begin{array}{l}1.41 \\
1.41 \\
\end{array}$ & $\begin{array}{l}1.42 \\
1.38 \\
\end{array}$ & 1.09 & 1.32 & 0.58 \\
\hline GS4 & 2 & $\begin{array}{r}0.0 \\
-10.0 \\
\end{array}$ & 3 & $\begin{array}{l}0.93 \\
0.93 \\
\end{array}$ & $\begin{array}{l}0.83 \\
0.82 \\
\end{array}$ & 0.72 & 0.82 & 0.47 \\
\hline
\end{tabular}

various simulation results. The total heat flux and its components are shown below the glazing system. It can be seen that the low-E coating is able to suppress radiative heat transfer in more than one gap but that it is less effective in the more remote gaps.

\section{CONCLUSIONS}

A direct comparison between measured and simulated heat transfer rates showed good agreement. A similar comparision (Wright and Sullivan, 1987) that examined the use of metal coatings in conjunction with Teflon films also provided good agreement. It can be concluded that highly. IR transparent intermediate glazings can be useful when high thermal resistance is desired. The VISION glazing system analysis program is useful not only for parametric and sensitivity investigations but can also be used with confidence to estimate U-values of specific glazing systems and to provide detailed insight into the mechanisms of coupled heat transfer.

\section{REFERENCES}

ElSherbiny, S.M., G.D. Raithby and K.G.T. Hollands (1982). Heat transfer by natural convection across vertical and inclined air layers. Journal of Heat Transfer, Vol. 104, pp. 96-102.

Hollands, K.G.T. and J.L. Wright. (1983). Heat loss coefficients and effective $\tau \alpha$ products for flat-plate collectors with diathermanous covers. Solar Energy, 30, No. 3, 211-216.

Sibbitt, B.E., and K.G.T.Hollands (1978). Radiant transmittance of Vcorrugated transparent sheets with application to solar collectors. ASME Paper No.76-WA-Sol-1, American Society of Mechanical Engineers, New York.

Siegel, R., and J.R. Howell (1972). Thermal Radiation Heat Transfer, Chapter 4, McGraw Hill Book Company.

Wilkinson, R.G. (1979). Radiative-conductive heat transfer through a honeycomb panel, M.A.Sc. Thesis, Department of Mechanical Engineering, University of Waterloo, Waterloo, Canada.

Wright, J.L. (1985). The computer simulation of glazing systems which incorporate teflon (FEP) inner glazings. Proceedings of the ISES/SESCI Intersol'85 Conference, Montreal, Canada.

Wright, J.L. and H.F. Sullivan (1987). Simulation and measurement of windows with metal films used in conjunction with teflon inner glazings. Proceedings of the International Congress on Building Energy Management, Lausanne, Switzerland, . 


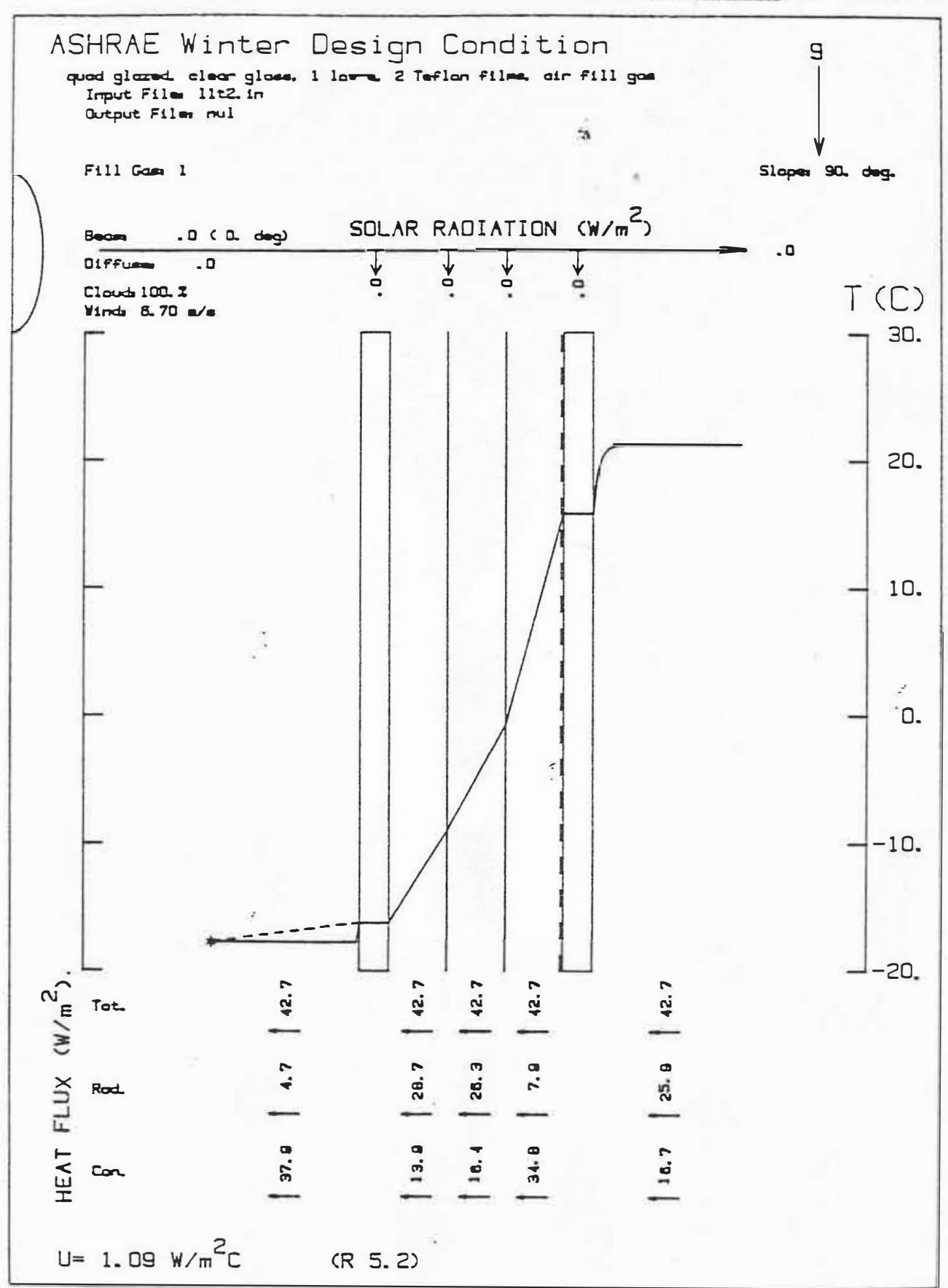

$\cong$ Fig. 1. Sample VISION graphic output showing glazing system GS3 之

\section{ACKNOWLEDGEMENTS}

The authors acknowledge financial support from The Renewable Energy Branch of The Department of Energy, Mines and Resources, Ottawa, Canada and Ford_Glass_Ltd. (Toronto,Canada) for_glass,_coatings and_optical_data. .

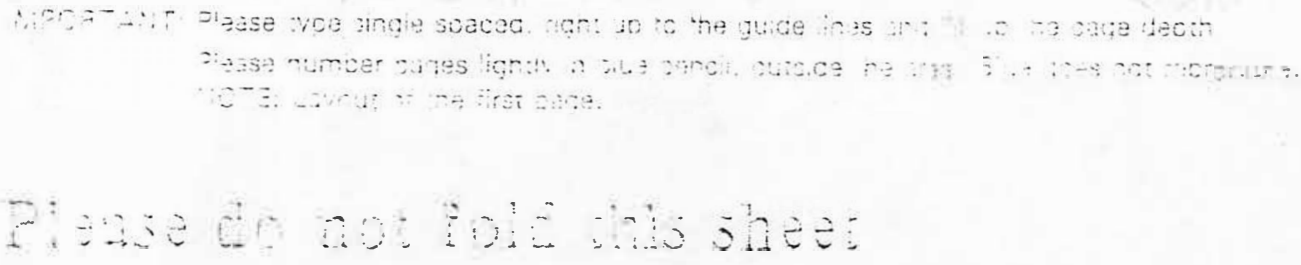

